\title{
MOBBING, SUBJECTIVE PERCEPTION, DEMOGRAPHIC FACTORS AND PREVALENCE OF BURNOUT SYNDROME IN NURSES
}

\author{
Šárka Vévodová, Jiří Vévoda, Bronislava Grygová \\ Department of Humanities and Social Sciences, Faculty of Health Sciences, Palacký University in Olomouc, Olomouc, Czech Republic
}

\section{SUMMARY}

Objectives: The aim of the study was to assess the prevalence of burnout syndrome and mobbing, to determine their mutual relationship, and to identify predictors related to the probability of occurrence of burnout syndrome in general nurses working in hospitals.

Methods: The work is designed as a cross-sectional study. The research took place in 2018 and the sample included 250 general nurses. Statistical evaluation was performed by means of descriptive statistics, Spearman's correlation coefficient, and logistic regression. Three standardized questionnaires were used - Maslach Burnout Inventory, Negative Questionnaire Act and SUPSO.

Results: The research revealed burnout syndrome in the area of emotional exhaustion in $28.8 \%$ of nurses, of depersonalization in $15.2 \%$, and in the area of personal accomplishment in $38.4 \% .51 .2 \%$ of nurses never experienced mobbing at workplace, one act of mobbing over the last six months was reported by $17.6 \%$ of respondents, two and more acts by $31.2 \%$. Logistic regression revealed that the probability of occurrence of burnout syndrome in the area of emotional exhaustion is influenced by age, sex and by the size of an urban area, it is increased by anxiety and depression. In the area of depersonalization the probability of incidence increases with impulsiveness and dejection. In the area of personal accomplishment the probability of burnout syndrome incidence is increased by the lack of psychological wellbeing and activeness, by restlessness and impulsiveness. Though there were found significant relationships between all component parts of burnout syndrome and mobbing, multivariate logistic regression did not show the impact of any component part of mobbing on the probability of occurrence of burnout syndrome.

Conclusions: The research revealed that the probability of burnout syndrome incidence is related to socio-demographic factors as well as to an individual's psychological states and perceptions. Direct impact of mobbing on the probability of burnout syndrome incidence was inconclusive.

Key words: mobbing, burnout, personality traits, occupational health, general nurse

Address for correspondence: J. Vévoda, Department of Humanities and Social Sciences, Palacký University in Olomouc, Hněvotínská 976/3, 77515 Olomouc, Czech Republic. E-mail: jiri.vevoda@upol.cz

https://doi.org/10.21101/cejph.a6211

\section{INTRODUCTION}

Occupational health and safety (OHS) is an important part of public health policy, which includes prevention of accidents and injuries at work $(1,2)$. The World Health Organization (WHO) defines health as a state of complete physical, mental and social wellbeing and not merely the absence of disease or infirmity.

Healthcare professionals can be adversely affected in quality of work and mental health by prolonged psycho-physical exhaustion, emotional exhaustion and lack of personal accomplishment. Agencies responsible for safety at work and professional healthcare services often deal with psychosocial work-related risks, including occupational stress, burnout, mobbing and violence at workplace.

\section{Burnout}

Freudenberger defines burnout as the exhaustion and energy depletion felt by the employees whose expectations were not met (3). Maslach adds frustration experienced by the employees who are continually exposed to their clients' problems (4).
Burnout syndrome involves the state of physical, emotional and psychological exhaustion due to great expectations and chronic work-related stress (5).

Burnout syndrome is typically observed in the so-called helping professions including healthcare professionals. On a daily basis, human care service providers are exposed to physical and psychological problems of the patients and their families and face problems of working conditions such as overload, lack of healthcare staff and its high fluctuation, lack of physicians' or colleagues' support, prolongation of patients lives, mobbing, lack of social support, etc. $(6,7)$. In some EU countries burnout syndrome is recognized as an occupational disease and it is also compensated for, while in other countries it is considered an occupational disease without compensation offered, and in other countries it is still not on the list of occupational diseases (8).

Within EU countries Lithuania has burnout syndrome on the List of Occupational diseases.

In seven EU countries burnout syndrome may be considered as an occupational disease. In three EU countries burnout syndrome may be acknowledged as an occupational disease. The fact is that burnout syndrome is not considered as a separate diagnosis and 
is classified under Z (8). WHO classifies burnout syndrome as an occupational phenomenon. In the Czech Republic burnout syndrome is classified within the International Classification of Diseases - version 10 under 273.0 - burnout, state of exhaustion. However, it is not considered an occupational disease (ICD version 11 has been in the process of translation into Czech; the Czech translation is expected in 2022).

However, burnout can be perceived as a syndrome, not as a disease, a group of symptoms that collectively indicate or characterize a disease. The clinical picture of burnout is very variable.

\section{Mobbing}

According to Leymann "mobbing refers to a social interaction through which one individual (seldom more) is attacked by one or more (seldom more than four) individuals almost on a daily basis and for periods of many months, bringing the person into an almost helpless position with a potentially high risk of expulsion" (9).

In the healthcare sector there is the highest proportion of employees exposed to unfavourable social behaviours (physical and verbal violence, intimidation at work) (10). Mobbing affects not only its victim and work organization but society as a whole (11), it shows a negative impact on an individual's health and overall wellbeing, and may result in both psychological and physical health problems, post-traumatic stress disorder, burnout syndrome, frequent job changing and lower work satisfaction (12). Employees who are victims of mobbing show significantly more symptoms of psychological stress and exhaustion (13).

\section{Relationship between Mental State, Mobbing and Burnout Syndrome}

When an individual faces psychosocial risks at workplace, the structure and dynamics of their current mental state plays a vital role.

Current research proves the relationship between mobbing and burnout syndrome in all its component parts (EE, DP, PA) $(14,15)$. Nurses experiencing mobbing show significantly higher level of emotional exhaustion and lower level of mental health (16). We can find other parallels between burnout syndrome and mobbing, e.g. burnout stages are comparable to mobbing stages, such as increased efforts at work, repression of conflicts and demands, or social isolation. Therefore, burnout may result from a long-lasting mobbing, and mobbing may be one of the main causes of burnout. To understand how mobbing triggers burnout is important for its prevention and control (17).

\section{Research Goal}

The aim is to examine the links between burnout syndrome, mobbing, socio-demographic factors, and dynamics of subjective perceptions and mental states. The study deals with four sub-goals focused on burnout syndrome degree, mobbing degree, relationship between the variables observed and burnout syndrome, and determination of predictors with statistically significant impact on the possibility of occurrence of burnout syndrome.

\section{MATERIALS AND METHODS}

The work is designed as a cross-sectional study using standardized questionnaires: Maslach Burnout Inventory (MBI), Negative Acts Questionnaire (NAQ), and SUPSO.

We did not aim to make a representative sample for the Czech Republic as a whole, we worked with selected hospitals from the Olomouc region. 400 questionnaires were distributed between June 1, 2018 and December 31, 2018. 258 questionnaires were returned, 8 were excluded due to incorrect completion.

The data were statistically processed with descriptive statistics, Spearman's correlation coefficient, and logistic regression at the confidence level $=95 \%$ and $99 \%$. MS Excel 2016 and IBM SPSS Base 19 were used for the statistical evaluation.

\section{Sample of Respondents}

The sample included 250 general nurses who worked in the position for at least 1 year (i.e., with adaptation to the work). Completed questionnaires in envelopes were placed anonymously into boxes at the workplaces.

The sample included 230 women and 20 men; mean age was 34.4 years $(\mathrm{SD}=8.16$, min-max: $21-51)$; mean length of employment 10.8 years $(\mathrm{SD}=8.2$, min-max: $1-32)$. The sample description is summarized in Table 1.

Table 1. Basic characteristics of the sample - number of returned questionnaires $(N=250)$

\begin{tabular}{|c|c|c|c|}
\hline \multicolumn{2}{|c|}{ Basic characteristics of sample } & \multirow{2}{*}{$\frac{n}{20}$} & \multirow{2}{*}{$\begin{array}{c}\% \\
8.00\end{array}$} \\
\hline Sov & Male & & \\
\hline ה & Female & 230 & 92.00 \\
\hline \multirow{5}{*}{ Education } & Secondary + GCSE & 80 & 32.00 \\
\hline & $\begin{array}{l}\text { Higher technical education } \\
\text { (specialist) }\end{array}$ & 24 & 9.60 \\
\hline & University bachelor's degree & 136 & 54.40 \\
\hline & University master's degree & 8 & 3.20 \\
\hline & Missing & 2 & 0.80 \\
\hline \multirow{3}{*}{ Work position } & Superior & 38 & 15.20 \\
\hline & Subordinate & 202 & 84.20 \\
\hline & Missing & 10 & 4.00 \\
\hline \multirow{8}{*}{ Residence } & Village of up to 999 inhabitants & 34 & 13.60 \\
\hline & Village of 1,000 to 1,999 inhabitants & 28 & 11.20 \\
\hline & Village of 2,000 to 4,999 inhabitants & 32 & 12.80 \\
\hline & Town of 5,000 to 19,999 inhabitants & 46 & 18.40 \\
\hline & $\begin{array}{l}\text { Town of } 20,000 \text { to } 49,999 \text { inhabit- } \\
\text { ants }\end{array}$ & 38 & 15.20 \\
\hline & $\begin{array}{l}\text { Town of } 50,000 \text { to } 89,999 \text { inhabit- } \\
\text { ants }\end{array}$ & 30 & 12.00 \\
\hline & $\begin{array}{l}\text { Town of } 90,000 \text { and more inhabit- } \\
\text { ants }\end{array}$ & 36 & 14.40 \\
\hline & Missing & 6 & 2.40 \\
\hline
\end{tabular}


The sample was divided into two groups according to the burnout syndrome degree detected: group N1 (employees not at risk of burnout syndrome $-\mathrm{MBI}$ cut points: $\mathrm{EE}=26$; $\mathrm{DP}=12$; $\mathrm{PA}=32$ ), and group N2 (employees at risk and with verified burnout syndrome $-\mathrm{MBI}$ cut points: $\mathrm{EE}=27$; $\mathrm{DP}=13$; $\mathrm{PA}=31)$.

\section{Burnout Measurement}

To measure the degree of burnout we used the Maslach Burnout Inventory (MBI) developed by Maslach and Jackson in 1981 (18). The MBI questionnaire was translated into Czech and approved by Havrdová et al. (19).

The MBI measures burnout in the areas of emotional exhaustion (EE), depersonalization (DP), and personal accomplishment (PA). The EE subscale (9 items) describes feelings of being emotionally exhausted due to work. The PA subscale ( 8 items) describes beliefs of one's competence and accomplishment at work. The DP subscale (5 items) describes detached and impersonal treatment of patients. Each of the 22 items asks nurses to describe their feelings on a seven-point scale, ranging from never having such feelings to having such feelings a few times a week (18).

In our present study Cronbach's $\alpha$ was 0.78 for the total scale, for sub-scales it was 0.58 (EE), 0.76 (DP), and 0.56 (PA), respectively.

\section{Mobbing Measurement}

To measure the experience of being exposed to mobbing, bullying-related behaviours and situations we used the Negative Acts Questionnaire-Revised (NAQ-R) (20). The Czech language version of NAQ-R was approved by Cakirpaloglu et al. (21). The questionnaire consists of 23 items, where high values signal that the person feels a victim of mobbing.

The NAQ-R involves two mobbing measurement strategies: behavioural (items 1-22) and self-reporting (item 23). In Part 1 (items 1-22) the respondents are asked how often they have been subjected to specific negative behaviours or situations at their workplace. The response format is Likert scale from 1 (never) to 5 (every day).

The respondents were asked about their experience at work during the last 6 months. Those who experienced one or more negative acts at least once a week over the period of 6 months were classified as targets of bullying according to Leymann's criteria for bullying assessment (22).

In Part 2 (self-report) the question is: "Have you been bullied at your workplace?" The response format is Likert scale from 1 (never) to 5 (every day).

The NAQ-R comprises three subscales associated with the following factors: $\mathrm{F} 1=$ work-related bullying $(7$ items, e.g. being ordered to do work below one's level of competence), F2 = person-related bullying (12 items, e.g. being ignored or excluded), and F3 = physically threatening behaviour ( 3 items, e.g. threats of violence or physical abuse or actual abuse).

In our study, Cronbach's $\alpha$ was 0.91 for the total scale, 0.90 , 0.77 and 0.73 for person-related, work-related and physicalrelated bullying, respectively.

The NAQ-R was developed by the Bergen Bullying Group and is available free of charge for non-profit research purposes.

\section{Structure and Dynamics of Subjective Perceptions and Mental States Measurement}

The SUPSO questionnaire describes and assesses the structure and dynamics of subjective perceptions, experiences and mental states (23). It is the result of factor analysis of operationally defined and pragmatically conceived scales consisting of 28 adjectives. The components of psychological state assessed are the following: $\mathrm{P}=$ psychological wellbeing, $\mathrm{A}=$ activeness, $\mathrm{O}=$ impulsiveness, ability to take one's mind off things, $\mathrm{N}=$ psychological restlessness, irritation, $\mathrm{D}=$ psychological depression, feelings of exhaustion, $\mathrm{U}=$ anxiety, apprehension, $\mathrm{S}=$ dejection. Gross scores are in the interval from 0 to 16 for each component part.

Psychometric qualities of SUPSO focused on the validity in terms of the contents and criteria, as well as on the reliability of structure and dynamics of psychological states assessment. We may mention here e.g. the correlations with Eysenck PEN questionnaire and Beck Depression Inventory (23).

The questionnaire was purchased from the company Psychodiagnostika Brno s.r.o.

\section{RESULTS}

The statistically processed data summarized in Table 2 show the results of three dimensions of burnout among nurses. In the EE scale $28.8 \%$ of nurses experienced a high level of exhaustion, and $47.2 \%$ a low level. In the DP scale $15.2 \%$ of respondents were at a high level of depersonalization and $58.4 \%$ at a low level. In the PA scale $36.8 \%$ of nurses experienced low levels of personal accomplishment, i.e. burnout.

Mobbing was experienced by $17.60 \%$ of respondents $(n=44)$ according to Leymann's criterion ( 1 act of bullying over the last

Table 2. Distribution of three dimensions of burnout $(N=250)$

\begin{tabular}{|l|c|c|c|c|}
\hline Burnout dimensions & $\mathbf{n}$ & $\%$ & Mean & SD \\
\hline Emotional exhaustion (EE) & 118 & 47.20 & 10.85 & 4.33 \\
\hline Low & 56 & 22.40 & 22.39 & 2.26 \\
\hline Moderate & 72 & 28.80 & 37.40 & 7.55 \\
\hline High - burnout & 4 & 1.60 & & \\
\hline Missing & 146 & 58.40 & 2.11 & 1.79 \\
\hline Depersonalization (DP) & 62 & 24.80 & 7.49 & 1.01 \\
\hline Low & 38 & 15.20 & 15.20 & 4.45 \\
\hline Moderate & 4 & 1.60 & & \\
\hline High - burnout & 92 & 36.80 & 22.10 & 7.52 \\
\hline Missing & 56 & 22.40 & 36.83 & 1.91 \\
\hline Personal accomplishment (PA) & 96 & 38.40 & 45.31 & 6.66 \\
\hline Low - burnout & 6 & 2.40 & & \\
\hline Moderate & & \\
\hline High & \multicolumn{5}{|l|}{} \\
\hline Missing &
\end{tabular}


Table 3. Mobbing frequency $(N=250)$

\begin{tabular}{|l|c|c|}
\hline & Frequency & $\%$ \\
\hline Never & 128 & 51.20 \\
\hline One act over the last 6 months & 44 & 17.60 \\
\hline Two or more acts over the last 6 months & 78 & 31.20 \\
\hline Total & 250 & 100.00 \\
\hline
\end{tabular}

6 months), and by $31.20 \%$ of respondents $(\mathrm{n}=78)$ according to Leymann's rigorous criterion -2 or more acts of bullying over the last 6 months (Table 3 ).

The questionnaire item 23 ("Have you been bullied at work?") answers were as follows: $87.20 \%(\mathrm{n}=218)$ respondents reported that they were not victims of mobbing at work during the last 6 months, $9.60 \%(\mathrm{n}=24)$ sometimes, $2.40 \%(\mathrm{n}=6)$ monthly, $0.80 \%$ $(\mathrm{n}=2)$ stated they were bullied several times a week, and no one was bullied every day.

For the correlation analysis, Spearman's correlation coefficient was calculated. The analysis between mobbing and burnout syndrome revealed the strongest correlation between person-related mobbing and emotional exhaustion (Table 4). Personal accomplishment (PA) correlates negatively with both burnout syndrome scales, emotional exhaustion (EE) and depersonalization (DP), and mobbing scales F1, F2, F3 (Table 4).

To assess the relationship of individual independent variables (predictors) and dependent variables EE, DP and PA the variables were divided into two subcategories, i.e. burnout present - burnout absent, a multivariate logistic regression method was applied. Pearson's correlation coefficient was used to determine the correlation between independent quantitative variables F1, F2, F3, Mobbing Sum Total, Psychological wellbeing, Activeness, Impulsiveness, Restlessness, Anxiety, Depression, Dejection. Correlation coefficient above 0.8 was found only between the variables Mobbing Sum Total and F1 $(r=0.890)$, and Mobbing Sum Total and F2 $(r=0.948)$. Therefore, the variable Mobbing Sum Total was not included into independent predictors. Table 5 gives values of odds ratio (OR) for each factor and the level of statistical significance (p). The model quality was assessed with Nagelkerke $\mathrm{R}^{2}$, which is an analogy of determination index in linear regression.

\section{Model of Logistic Regression}

Using a logistic regression model, the following five predictors were identified for statistically significant impact on the probability of burnout syndrome EE occurrence: sex, age, place of permanent residence size, anxiety and depression.

- In women the chance of burnout syndrome in EE scale is 0.049 times lower than in men;

- (95\% CI: 0.004-0.639);

- If there is an increase of one year in age, the chance to suffer from burnout syndrome in EE scale lowers 0.828 times $(95 \%$ CI: 0.706-0.970);

- In case a person lives in a town of 50,000-90,000 inhabitants, the chance to suffer from burnout syndrome in EE scale increases 103 times (95\% CI: 9.7-1,089), compared to a person living in a municipality up to 5,000 inhabitants. In case a person lives in a town of more than 90,000 inhabitants, the chance to suffer from burnout syndrome in EE scale increases 42 times (95\% CI 3.5-511), compared to a person living in a municipality up to 5,000 inhabitants;

- In case the Anxiety scale increases by 1 unit, the chance that a person will suffer burnout syndrome increases 2.125 times (95\% CI: 1.099-4.111);

- In case the Depression scale increases by 1 unit, the chance that a person will suffer burnout syndrome increases 5.994 times (95\% CI: 2.493-14.408).

Using a logistic regression model, two predictors were identified with statistically significant impact on the probability of burnout syndrome DP incidence: Impulsiveness and Dejection.

- In case the Impulsiveness scale increases by 1 unit, the chance that a person will suffer burnout syndrome increases 1.504 times (95\% CI: $1.007-2.248)$;

- In case the Dejection scale increases by 1 unit, the chance that a person will suffer burnout syndrome increases 1.471 times (95\% CI: 1.064-2.034).

Using a logistic regression model, four predictors were identified with statistically significant impact on the probability of burnout syndrome PA incidence: Psychological wellbeing, Activeness, Impulsiveness and Restlessness.

- In case the Psychological wellbeing scale increases by 1 unit, the chance that a person will suffer burnout syndrome decreases 0.573 times (95\% CI: $0.408-0.806$ );

- In case the Activeness scale increases by 1 unit, the chance that a person will suffer burnout syndrome decreases 0.625 times (95\% CI: 0.449-0.869);

Table 4. Correlation coefficients between variables

\begin{tabular}{|c|c|c|c|c|c|c|}
\hline & $\begin{array}{c}\text { Work-related } \\
\text { bullying } \\
\text { (F1) }\end{array}$ & $\begin{array}{l}\text { Person-related } \\
\text { bullying } \\
\text { (F2) }\end{array}$ & $\begin{array}{c}\text { Physically } \\
\text { threatening } \\
\text { behaviour (F3) }\end{array}$ & $\begin{array}{l}\text { Emotional } \\
\text { exhaustion } \\
\text { (EE) }\end{array}$ & $\begin{array}{l}\text { Depersonalization } \\
\text { (DP) }\end{array}$ & $\begin{array}{c}\text { Personal } \\
\text { accomplishment } \\
\text { (PA) }\end{array}$ \\
\hline Work-related bullying (F1) & 1.000 & $0.715^{\star \star}$ & $0.502^{\star *}$ & $0.322^{\star *}$ & $0.150^{*}$ & $-0.152^{*}$ \\
\hline Person-related bullying (F2) & & 1.000 & $0.622^{* *}$ & $0.399^{* *}$ & $0.349^{* *}$ & $-0.253^{\star *}$ \\
\hline Physically threatening behaviour (F3) & & & 1.000 & $0.255^{\star *}$ & $0.216^{* *}$ & $-0.217^{\star *}$ \\
\hline Emotional exhaustion (EE) & & & & 1.000 & $0.526^{* *}$ & $-0.409^{* *}$ \\
\hline Depersonalization (DP) & & & & & 1.000 & $-0.477^{\star *}$ \\
\hline Personal accomplishment (PA) & & & & & & 1.000 \\
\hline
\end{tabular}

${ }^{*} \mathrm{p}$-value less than $0.05 ;{ }^{* *} \mathrm{p}$-value less than 0.01 


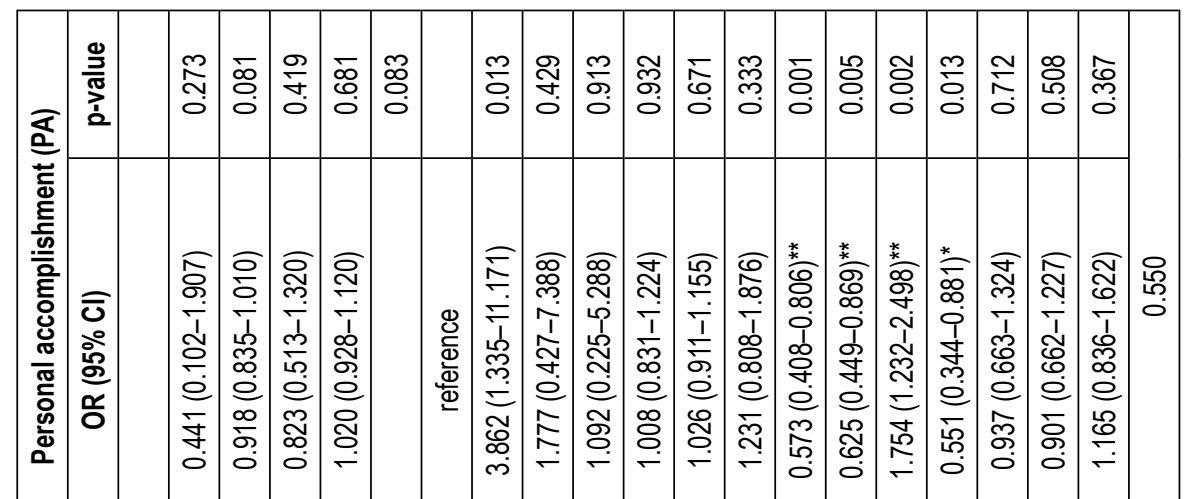

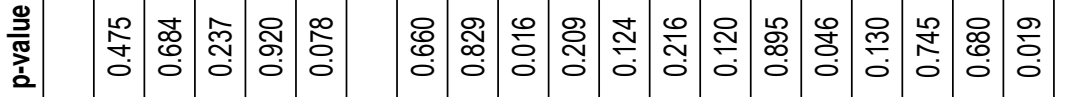

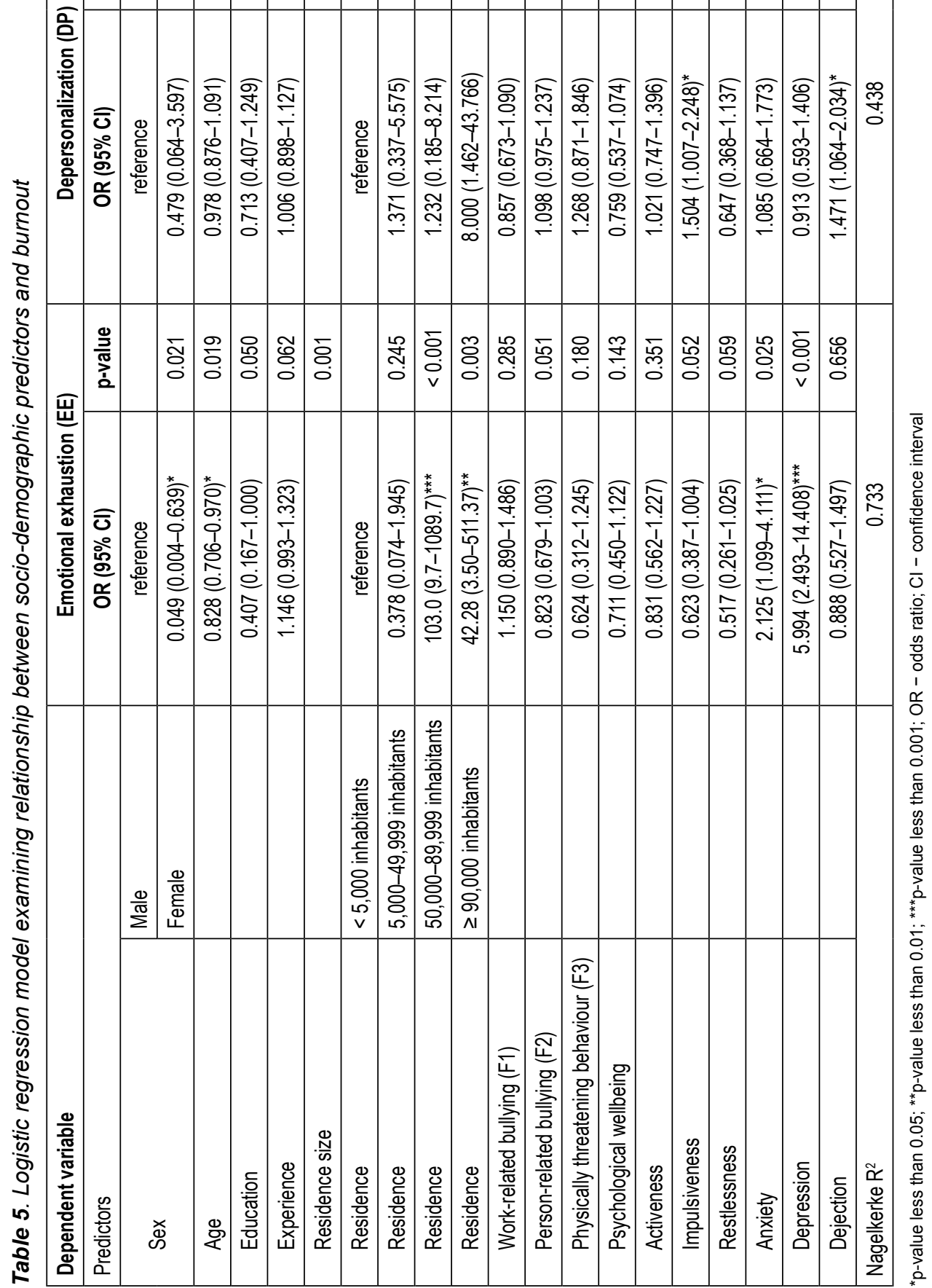


- In case the Impulsiveness scale increases by 1 unit, the chance that a person will suffer burnout syndrome increases 1.754 times (95\% CI: 1.232-2.498);

- In case the Restlessness scale increases by 1 unit, the chance that a person will suffer burnout syndrome decreases 0.551 times (95\% CI: 0.344-0.881).

\section{DISCUSSION}

Changes in work conditions over the last decades, i.e. transfer of the workforce into a tertiary sector of the national economy, means also the transfer from physical risks to psychosocial risks, which brings about a new challenge in terms of protection and safety at work. Healthcare professionals as the so-called helping professions are considerably endangered by these risks.

The research aimed to determine the degree of burnout syndrome, mobbing, and their correlations, as well as to identify the predictors showing significant relationship to the probability of burnout syndrome incidence.

We found a significant prevalence of burnout syndrome in our sample (250 respondents). For 96 nurses with burnout syndrome (38.4\%), 77 cited emotional exhaustion (22.8\%), 38 cited depersonalization and low personal accomplishment (15.2\%). To a large degree our results agree with the meta-analysis that revealed $31 \%$ nurses suffering from high emotional exhaustion, $24 \%$ nurses suffering from high depersonalization, and $38 \%$ nurses suffering from low personal accomplishment in $63.15 \%(\mathrm{n}=24)$ of the studies reviewed (24). Our research shows that PA is opposite to both EE and DP, and to personrelated, work-related and physical-related mobbing.

Our research recorded mobbing prevalence - one act of mobbing over the last six months was reported by 44 nurses (17.6\%), two acts by 78 nurses (31.2\%). Cakirpaloglu et al. reported $20 \%$ victimization prevalence among the employees in the Czech Republic. Mobbing prevalence in nurses seems to be higher than in common population (21). The published data suggests that as many as $43 \%$ of nurses have experienced mobbing (25). On the contrary, nurses in the Czech Republic seem to feel subjectively less victimized - only two nurses (less than 1\%) answered they felt like mobbing victims. This is different from e.g. the research by Dåderman and RagnestålImpola stating $8.7 \%$ of victimized nurses (26).

The research results also suggest that person-related attacks violate the victim's self-esteem and cause a high degree of emotional exhaustion. This is in agreement with the conclusion of the study by Sá and Fleming stating that bullied nurses show significantly higher levels of emotional exhaustion (16).

In spite of the fact that significant relationships were found between all component parts of burnout syndrome and mobbing, the multivariate logistic regression did not prove the influence of any part of mobbing on the probability of burnout syndrome incidence. Mobbing at workplace is related - similarly to burnout syndrome - to depression, dejection, anxiety, subjective wellbeing and activeness of a victim (21).

The probability of syndrome burnout occurrence within the scale of emotional exhaustion in general nurses increases significantly with the increasing municipality size. A nurse living in the municipality between 50 and 90 thousands of inhabitants faces burnout syndrome 103 times more compared to a nurse living in a municipality up to 5,000 inhabitants. This may be explained by better social support and slower life tempo. Social support is a significant protective factor of burnout syndrome $(27,28)$. The work of Shitvani a Shirvany proved a significant role of social support and found the difference of the role of social support in women living in towns and villages (27). Studies prove that working in urban areas significantly increases burnout syndrome incidence (29-31). Saijo et al. demonstrated greater job demands, less job control, and greater exhaustion among urban hospital physicians compared to rural hospital ones (30).

In employees who transferred their jobs from village to town settings there was found a higher degree of burnout syndrome. This is explained by increased job and personal strain (32). People in rural areas are closer to nature than urban people. Nature, including interaction with plants, animals and water sources, can contribute to our health condition and wellbeing (33). Moreover, people living in villages and countryside devote more time to gardening which is recommended as both prevention and therapy of burnout syndrome and it has beneficial effects on mental health in general (34).

The results also suggest that the probability of syndrome burnout incidence is related to the age of a nurse. The older the nurse the lower the probability of burnout. However, the age as a burnout syndrome predictor is open to dispute because several works proved the age as a neutral factor (35). Yet other studies state that younger age is a significant factor of burnout incidence (35). Another study argues that the occurrence of burnout syndrome in the EE scale initially increases with age, and then starts to decrease as the workers are getting older (37).

Sex is another socio-demographic predictor of burnout syndrome incidence that remains open to debate. Our research shows that in men burnout is more probable to occur than in women. This corresponds to a previous research by Hatch et al. concluding that there is lower burnout in females (38). However, LaFavet et al. state that burnout criteria are met by more women (64.9\%) than men (57.8\%) (37). Our results may be biased due to a lower number of male respondents working as general nurses.

The probability of occurrence of burnout syndrome is related to several indicators of psychological state which are determined with SUPSO questionnaire. The highest probability of higher burnout in the EE scale was found in the factors of depression and anxiety. In their systematic review, Bianchi et al. report that inventories assessing burnout - specifically the area of emotional exhaustion - show positive correlation with depressive symptoms (39). Ding et al. found positive correlation between EE and cynicism (DP) and anxiety symptoms (40). According to van Dam depression and anxiety appeared to be strongly related, whilst exhaustion appeared to be related to general fatigue, cynicism, and depression (41).

In the DP scale the probability of burnout syndrome is increased by impulsiveness and dejection. SUPSO defines impulsiveness as an uncontrolled, spontaneous release of energy and psychological tension (23). It is characterized by moodiness, difficult self-control, quick temper, irritation, and uncontrolled aggression (23). In case an employee performs a monotonous 
job without airing of psychological tensions the probability of burnout syndrome increases. Saber and Ali reported that there exists a significant positive correlation between competitive anxiety, sports perfectionism, and impulsiveness with burnout among professional athletes (42).

Our research also showed that in the DP scale the probability of burnout syndrome incidence is increased by dejection. SUPSO defines dejection as experiencing of negative consequences of psychological burden (23). A person is sad, lonely, and he/she perceives patients as objects which are a part of the outer environment. Dejection, as a factor of burnout, is observed also in students of nursing care programmes (43). However, dejection is a less specific symptom of burnout.

In the PA scale the probability of burnout syndrome incidence decreases with better psychological wellbeing and activeness. SUPSO defines psychological wellbeing as a feeling of satisfaction, good mood, experiences of euphoria and self-confidence (23). This agrees with the conclusions by Kareaga et al. (44).

The probability of burnout is also reduced by activeness. SUPSO defines activeness as feelings of strength, energy, and desire to do something (23).

Our research shows that the probability of burnout syndrome incidence in nurses is more related to psychological states and perceptions of an individual and to socio-demographic factors than to mobbing. It seems that psychological states and perceptions of an individual may serve as a moderating factor between mobbing and burnout syndrome. To verify this hypothesis further research is necessary.

\section{Limitations of the Study}

Of course, the presented study is not flawless, and the authors would like to mention three major limitations:

Respondents were not randomly selected.

Cut-off points are based on the US data as there do not exist Czech population standards and, therefore, the Czech cut-off points may be different.

The results may be biased due to a low number of male respondents included in the sample.

Further research and more representative sample (respondents from other regions) is necessary.

\section{CONCLUSION}

Our research shows a high prevalence of both burnout syndrome and mobbing among general nurses. The probability of burnout incidence is related not only to socio-demographic factors, sex, age and residence of an individual, but also to their psychological state, anxiety, depression, dejection, impulsiveness, activeness, restlessness, and psychological wellbeing. It was also shown that mobbing does not directly increase the probability of occurrence of burnout syndrome.

\section{Adherence to Ethical Standards}

The research was approved by the Ethics Committee of the Faculty of Health Sciences, Palacký University in Olomouc, and by Ethics Committees and managements of the respective hospitals.

\section{Acknowledgements}

This study was supported by $\mathrm{MH} \mathrm{CZ} \mathrm{-} \mathrm{DRO} \mathrm{(Palacký} \mathrm{University} \mathrm{in}$ Olomouc, 61989592)

\section{Conflict of Interests}

None declared

\section{REFERENCES}

1. Frumkin H, editor. Environmental health: from global to local. 2nd. San Francisco: JosseyBass; 2010.

2. Jennings B. Environmental and occupational public health. In: Barrett DH, Ortmann LW, Dawson A, Saenz C, Reis A, Bolan G, editors. Public health ethics: cases spanning the globe. New York: Springer; 2016. p. 177-202.

3. Freudenberger H. Staff burn-out. J Soc Issues. 1974;30(1):159-65.

4. Maslach C. Burned-out. Hum Behav. 1976;9(5):16-22.

5. Kallwass A. Burnout at work and in personal life. Prague: Portál; 2007. (In Czech.)

6. Lim J, Bogossian F, Ahern K. Stress and coping in Australian nurses: a systematic review. Int Nurs Rev. 2010;57(1):22-31.

7. Niiyama E, Okamura H, Kohama A, Taniguchi T, Sounohara M, Nagao M. A survey of nurses who experienced trauma in the workplace: influence of coping strategies on traumatic stress. Stress Health. 2009;25(1):3-9.

8. Lastovkova A, Carder M, Rasmussen H, Sjoberg L, Groene G, Saun $\mathrm{R}$, et al. Burnout syndrome as an occupational disease in the European Union: an exploratory study. Indust Health. 2018;56(2):160-5.

9. Leymann H. The content and development of mobbing at work. Eur J Work Organ Psych. 1996;5(2):165-84.

10. Giaccone M, Di Nunzio D. Violence and harassment in European workplaces: extent, impacts and policies [Internet]. Dublin: Eurofound; 2015 [cited 2020 Aug 23]. Available from: https://www.eurofound.europa.eu/ sites/default/files/ef_comparative_analytical_report/field_ef_documents/ ef1473en.pdf.

11. Einarsen S, Hoel H, Zapf D, Cooper C, editors. Bullying and harassment in the workplace: developments in theory, research, and practice. 2nd ed. New York: Taylor \& Francis; 2011.

12. Nielsen M, Einarsen S. Outcomes of exposure to workplace bullying: a meta-analytic review. Work Stress. 2012;26(4):309-32.

13. Agervold M, Mikkelsen EG. Relationships between bullying, psychosocial work environment and individual stress reactions. Work Stress. 2004;18(4):336-51.

14. Laschinger H, Grau A, Finegan J, Wilk P. New graduate nurses' experiences of bullying and burnout in hospital settings. J Adv Nurs. 2010;66(12):2732-42.

15. Einarsen S, Matthiesen S, Skogstad A. Bullying, burnout and well-being among assistant nurses. J Occup Health Safety. 1998;14(6):563-8.

16. Sá L, Fleming M. Bullying, burnout, and mental health amongst Portuguese nurses. Iss Mental Health Nurs. 2008;29(4):411-26.

17. Laschinger HKS, Fida R. A time-lagged analysis of the effect of authentic leadership on workplace bullying, burnout, and occupational turnover intentions. Eur J Work Organ Psych. 2014;23(5):739-53.

18. Maslach C, Jackson S. The measurement of experienced burnout. J Organ Behav. 1981;2(2):99-113.

19. Havrdová Z, Šolcová I, Hradcová D, Rohanová E. Organizational culture and burnout. Ceskoslov Psychol. 2010;54(3):235-48. (In Czech.)

20. Einarsen S, Hoel H, Notelaers G. Measuring exposure to bullying and harassment at work: validity, factor structure and psychometric properties of the Negative Acts Questionnaire-Revised. Work Stress. 2009;23(1):24-44.

21. Cakirpaloglu P, Šmahaj J, Dobešová Cakirpaloglu S, Zielina M. Bullying at work: reliability and validity of the Czech version of the Negative Acts Questionnaire-Revised. Ceskoslov Psychol. 2017;61(6):546-58. (In Czech.)

22. Leymann H. Mobbing and psychological terror at workplaces. Violence Vict. 1990;5(2):119-26.

23. Mikšík O. SUPSO questionnaire: manual for manual data evaluation version. Brno: Psychosiagnostika; 2004. (In Czech.)

24. Molina-Praena J, Ramirez-Baena L, Gómez-Urquiza JL, Cañadas GR, De la Fuente EI, Cañadas-De la Fuente GA. Levels of burnout and risk 
factors in medical area nurses: a meta-analytic study. Int J Environ Res Public Health. 2018;15(12):2800. doi: 10.3390/ijerph15122800.

25. Geçici B, Sağkal TA. A survey about the state of nurses who experienced mobbing in Odemis. Maltepe Üniversitesi Hemşirelik Bilim ve Sanatı Dergisi. 2011;4(1):53-62. (In Turkish.)

26. Dåderman A, Ragnestål-Impola C. Workplace bullies, not their victims, score high on the dark triad and extraversion, and low on agreeableness and honesty-humility. Heliyon. 2019;5(10):e02609. doi: 10.1016/j.heliyon.2019.e02609.

27. Shirvani M, Shirvani F. A Study of cultural and social factors affecting urban and rural women's burnout in shahrekord township. UCT J Soc Sci Human Res. 2015;3(2):81-6.

28. Lee EJ, Sung MH, Ahn HK, Kim YA. Effect of incivility, resilience, and social support experienced by nursing students on burnout in clinical practice. Korean J Wom Health Nurs. 2019;25(1):86-98.

29. Balayssac D, Pereira B, Virot J, Collin A, Alapini D, Cuny D, et al. Burnout, associated comorbidities and coping strategies in French community pharmacies - BOP study: a nationwide cross-sectional study. PLoS One. 2017;12(8):e0182956. doi: 10.1371/journal.pone.0182956.

30. Saijo Y, Chiba S, Yoshioka E, Kawanishi Y, Nakagi Y, Ito T, et al. Job stress and burnout among urban and rural hospital physicians in Japan. Austral J Rur Health. 2013;21(4):225-31.

31. Dombrovskis V, Guseva S, Murasovs V. Motivation to work and the syndrome of professional burn-out among teachers in Latvia. Proc Soc Behav Sci. 2011;29:98-106.

32. Luo H, Yang H, Xu X, Yun L, Chen R, Chen Y, et al. Relationship between occupational stress and job burnout among rural-to-urban migrant workers in Dongguan, China: a cross-sectional study. BMJ Open. 2016;6(8): e012597. doi: 10.1136/bmjopen-2016-012597.

33. La Puma J. Nature therapy: an essential prescription for health. Alternativ Complement Therap. 2019;25(2):68-71.

34. Waberer M, Quendler E. Horticultural therapy for burnout patients at farms. In: 3rd international conference on safety, health and welfare in agriculture and agro - food systems "Ragusa SHWA 2012"; 2012 Sep 3-6; Ragusa, Italy. p. 402-4.
35. Yildirim İ. Relationships between burnout, sources of social support and sociodemographic variables. Soc Behav Personal. 2008;36(5):603-16.

36. Gómez-Urquiza JL, Vargas C, De la Fuente EI, Fernández-Castillo R, Cañadas-De la Fuente GA. Age as a risk factor for burnout syndrome in nursing professionals: a meta-analytic study. Res Nurs Health. 2017;40(2):99-110.

37. LaFaver K, Miyasaki J, Keran C, Rheaume C, Gulya L, Levin K, et al. Age and sex differences in burnout, career satisfaction, and well-being in US neurologists. Neurology. 2018;91(20):e1928-41. doi: 10.1212/ WNL.0000000000006497.

38. Hatch D, Freude G, Martus P, Rose U, Müller G, Potter GG. Age, burnout and physical and psychological work ability among nurses. Occup Med (Lond). 2018;68(4):246-54.

39. Bianchi R, Schonfeld I, Laurent E. Burnout - depression overlap: a review. Clin Psych Rev. 2015;36:28-41.

40. Ding Y, Qu J, Yu X, Wang S, Seedat S. The mediating effects of burnout on the relationship between anxiety symptoms and occupational stress among community healthcare workers in China: a cross-sectional study. PLoS One. 2014;9(9):e107130. doi: 10.1371/journal.pone.0107130.

41. van Dam A. Subgroup analysis in burnout: relations between fatigue, anxiety, and depression. Front Psychol. 2016;7:90. doi: 10.3389/fpsyg.2016.00090.

42. Saber A, Ali Z. Predicting sport burnout based on competitive anxiety, sport perfectionism and impulsivity in professional athletes. Sport Psychol Stud. 2018;6(22):99-112.

43. Wang M, Guan H, Li Y, Xing C, Rui B. Academic burnout and professional self-concept of nursing students: a cross-sectional study. Nurs Educ Today. 2019;77:27-31.

44. Kareaga AA, Ayestarán SA, Smith JC. Assessment of burnout and psychological wellbeing among health professionals in the Basque Country. Psychol Spain. 2009;13(1):62-71.

Received March 30, 2020

Accepted in revised form August 23, 2020 